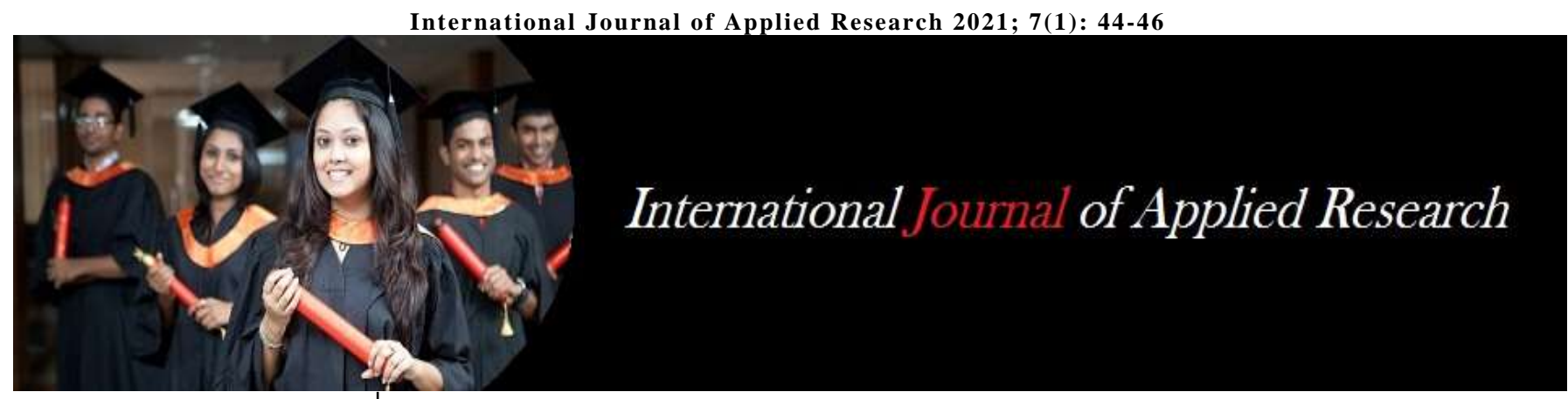

ISSN Print: 2394-7500

ISSN Online: 2394-5869

Impact Factor: 8.4

IJAR 2021; 7(1): 44-46

www.allresearchjournal.com

Received: 18-11-2020

Accepted: 26-12-2020

Sanjukta Bhaumik

Assistant Professor, Kristu

Jayanti College, Bengaluru,

Karnataka, India
Corresponding Author: Sanjukta Bhaumik Assistant Professor, Kristu Jayanti College, Bengaluru, Karnataka, India

\section{The challenges of peer-review process}

\section{Sanjukta Bhaumik}

DOI: https://doi.org/10.22271/allresearch.2021.v7.i1a.8149

\section{Abstract}

The peer-review method is an important pillar for publication. Peer review is designed to measure the validity, quality, and often the authentication of articles for publication. The purpose of peer review is to improve the quality of manuscripts and to identify suitable manuscripts for the journal. However, this process has many challenges too. Therefore, I aim to discuss different challenges of the peer review process through analyzing secondary data.

\section{Keywords: Manuscripts, secondary data, peer review}

\section{Introduction}

According to a guide for reviewing Developmental Neuroscience articles, the peer-review process has advantages for both the author and the readers. A good peer-review process can determine whether the topic is suitable for a particular journal or whether the quality of research is good or not. The peer-review method helps the researcher to build more logical arguments for the proposed phenomenon. Reviewers can help the authors to shape and arrange his/her observations in a more efficient way. However, several researchers have argued that the peer-review method is not a perfect process. Many scientists often claim that the unproductive peer-review process may posit a threat to both science and scientists. Therefore, I would like to discuss the challenges of the peer-review process by analyzing different secondary sources.

\section{History of the peer-review process}

The peer-review process is used to assess the quality of an individual manuscript. It has been considered as one of the yardsticks to judge the article's contribution to the entire academia. The history of the peer-review process can be traced back to England. The first record of an editorial pre-publication peer-review is from 1665 by Henry Oldenburg, the founding editor of Philosophical Transactions of the Royal Society at the Royal Society of London. The Medical Essays and Observations published by the Royal Society of Edinburgh in 1731 were probably the first peer-reviewed publication. In the 19th century, the peer-review method had started flourishing even more as many new disciplines started emerging out and the editors of journals in newly professionalized fields consulted with the colleague about the advantages of submissions. In the 20th century, the peer-review process became institutionalized with the advent of more number of scholarly articles. Therefore, a systematic and orderly publication process was needed where experts could evaluate the manuscripts objectively before publication. Since then, the peer-review method has been serving as a major scientific tool for journals to judge the quality of manuscripts. However, till the 19th century, the peerreview process was often performed by the editor-in-chief or editorial committee. Editors of scientific journals at that time made publication decisions without seeking outside feedback. Since the mid $20^{\text {th }}$ century only some of the medical journals started to appoint external reviewers for systematically assessing manuscripts.

\section{Nature and Purpose of peer-review}

Peer reviews can be conducted by a person or a group of people who has command over the subject. For Conferences, peer-review is conducted by a Programme Committee. The purpose of the peer review method is enormous. It works as a filter and ensures that only high-quality research is published in reputable journals. 
Secondly, peer review is structured to improve the quality of manuscripts that are deemed suitable for publication (Kelly et al. 2014) ${ }^{[3]}$. The research publication process covers a broad area of academic activity including assessment of colleagues' classroom teaching abilities, evaluation of experts of research grant and fellowship application submitted to different funding agencies, review by both editors and external referees of articles submitted to scholarly journals, evaluation of book proposals submitted to university and commercial presses, rating of papers and posters submitted to conferences by program committee chairs and assessments of quality, applicability, and interpretability of data sets (Lee et al., 2013).

\section{Challenges and Mechanisms of Peer review method}

For journals, an article is reviewed by the members of an Editorial board. In most cases, the author is completely unaware of the reviewer (single-blind peer-review) and in many cases; the reviewer and the author both are unaware of each other's identity (double-blind). A triple-blind peer review process ensures the anonymity of the author as well as the reviewer to the editor of a journal during the peer review process. In the case of Open peer review processes, the identities of both the author and the reviewer are open to each other. According to a study by Haffer and team, The British Medical Journal achieved success in the open peer review method nearly two decades ago while other reputed journals are still striving to attain it due to the nonengagement of their authors and reviewers (Haffar, Bazerbachi \& Murad, 2019) ${ }^{[2]}$.

The structure of the peer-review process has been designed to reduce biases in the peer-review process and to ensure peer impartiality (Lee et al., 2013). However, both methods have their challenges. Many researchers prefer a singleblind review of the double-blind method. To them, doubleblind is kind of 'black-box'. Nobody is sure what is inside. Andrew Tomkins and his colleagues argued that achieving complete anonymity is a myth (Tomkins, Zhang \& Heavlin, 2017) ${ }^{[17]}$. In their paper, they discussed three forms of possible bias in the peer review method. First, the Matilda effect proposed by Knobloch-Westerwick et al., in which papers from male first authors are evaluated to have greater scientific merit than papers from female first authors, Second the Mathew effect proposed by Robert K Merton where the recognition goes to already famous researchers for a new idea. Third, the experimental work by Blank, where he argued that reviewers are biased towards the fame and quality of certain institutions (ibid).

Richard Smith (2006) ${ }^{[6]}$ in his journal 'Peer review: a flawed process at the heart of Science and Journals' delineated different shortcomings of the peer review method. According to him, the peer review process is slow and expensive. Even in the 21st century, reviewers of reputable medical and science journals usually take one year to accept and publish a manuscript. In most cases, the reviewers are underpaid or often not paid at all. With the increasing numbers of open access journals, the publication charges are also increasing. The open-access model takes money from the author for the peer review process and publishes it on a particular website. Therefore, on one hand, the whole peer review system is moving towards capitalism by becoming more profitable and on the other hand, the process has been intensified by the scientific community. His second argument addressed the issue of inconsistency related to the review method. The nature of peer review is subjective and therefore conflict of interest arises. In most cases, the acceptance of manuscripts largely depends on the understanding of the reviewers. To Smith, evaluating manuscripts is as difficult as ranking famous painters. Sometimes differences of opinion between reviewers lead to rejection of papers.

\section{Gender Inequality}

Gender inequality in the field of scientific publication is quite common. The reputation of the author and sometimes the institutions, too, play a key role in case of deciding the fate of manuscripts. Smith has argued that the chance of plagiarism is very high if the journal members practice dishonesty. He further identified many ideas to improve the process namely, standardizing procedures; opening up the process; blinding reviewers to the identity of authors; reviewing protocols; training reviewers; being more rigorous in selecting and deselecting reviewers; using electronic review; rewarding reviewers; providing detailed feedback to reviewers; using more checklists; or creating professional review agencies (Smith, 2006) ${ }^{[6]}$.

\section{Methodology}

This paper aims to achieve its methodological understanding through secondary data analysis. Secondary data analysis is a process of systematic scientific investigation of data that was collected by some other researcher/researchers in publication. Here I have analyzed some of the secondary research-based data which served my purpose.

\section{Data Analysis}

Alex Holmes and Sally Hardy ("Gender bias in peer review - opening up the black box", 2019) examined the results of research undertaken by the Regional Studies Association on the relationship between author gender and peer review outcomes. They selected only binary gender for their study. For more authenticity of research, they deleted all the entries of individuals from the database. They have found that there were $63 \%$ male reviewers as compared to $37 \%$ female reviewers. In the case of numbers of review articles they had found that out of the total number of male reviewers, $40 \%$ reviewed more than one article. Out of the total number of female reviewers, $34 \%$ of them reviewed more than one article.

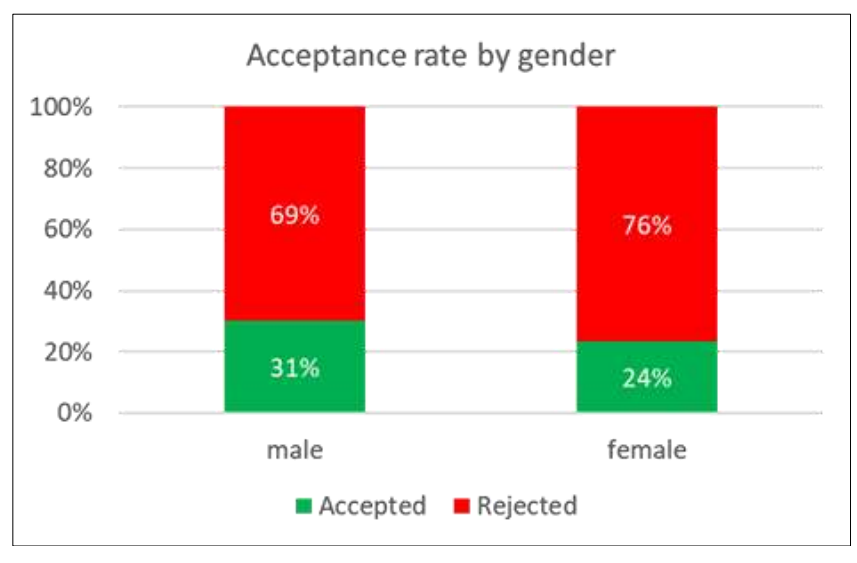

Fig 1: Image source:

https://blogs.lse.ac.uk/impactofsocialsciences/2019/03/08/ge nder-bias-in-peer- review-opening-up-the-black-box/ 
Another case study conducted by Richard Walker and team (Walker, Barros, Conejo, Neumann \& Telefont, 2015) ${ }^{[8]}$ found data from research databases including Frontiers, Spanish Computer Science Conferences, and International Computer Science Conferences. According to their observation, there is no bias exist on basis of the personal characteristics of the author/authors. However, they observed that sometimes the author's identity may influence the review scores. According to them the score distribution of authors during the peer review process is largely influenced by either the institution's name associated with the author or the language preference of the reviewers.

\section{Reduce bias in the peer review process}

Several studies suggested that bias is inevitable in the peer review process as long as human beings are associated with it. However, by adopting some strict guidelines, we at least can try to reduce the scope of biases in peer review. Therefore, Haffer and the team had suggested several methods to improve the peer review system. According to them, Penelope is a tool that can be beneficial for both the researchers and the reviewers (Haffar, Bazerbachi \& Murad, 2019) ${ }^{[2]}$. Further, they argued that more researches are needed to understand the review process thoroughly.

\section{Selection of a Peer}

Sometimes the quality of the review itself becomes a challenge. Almost all the journals want authors believe that the peer-review process is conducted by specialized authors in the particular field but unfortunately, this is not the case. Many times, the 'peer' is someone who is either a student or a PhD scholar. According to the report by Professor Bhushan Patwardhan from Savitribai Phule Pune University $88 \%$ of journals don't have proper editors or 'peers' or they don't follow the scientific peer-review process.

\section{The Peer-review scam}

Cat Ferguson, Adam Marcus and Ivan Oransky (Ferguson, Marcus and Oransky, 2014) ${ }^{[1]}$ in their paper have discussed how peer-review process has been subjected to malpractice and deception. The peer-review process is a time consuming affair as it demands loyalty and expertise. However, in case of Hyung-In Moon, a medical -plant researcher, the review process took shorter because he himself reviewed some of his articles. These types of cases are happening in India too. Researchers often try to cheat editors just to get their manuscripts accepted.

\section{Selection of an Editor}

The editor of the journal 'The Canadian Journal of Diabetics' (Lau, 2016) ${ }^{[4]}$ had suggested that the selection of an editor or the editorial board member is the most important aspect of a good peer- review process. These people should have sound knowledge of their respective subjects. The editorial board members should be highly trained to identify the quality manuscripts for their journals. The reviewers must have good knowledge of available research tools and software. They need to be ethically unbiased. All manuscripts need to undergo strict checking. The reviewers should have all the necessary software to check plagiarism.

\section{Conclusion}

After analyzing several quantitative data I can say that there are many challenges related to the peer review process which can directly impact the researchers in many ways. To me, more research into peer review is needed. However, it is difficult to form a unified model to address the flawed peer review processes. Therefore, different fields need different approaches to achieve the transparency and accountability in the peer review system.

\section{References}

1. Ferguson C, Marcus A, Oransky I. Publishing: The peer-review scam. Nature 2014;515(7528):480-482.

2. Haffar S, Bazerbachi F, Murad M. Peer Review Bias: A Critical Review. Mayo Clinic Proceedings, 2019:94(4):670-676. doi: 10.1016/j.mayocp.2018.09.004

3. Kelly J, Sadeghigh T, Adeli K. Peer Review in Scientific Publications: Benefits, Critiques, \& A Survival Guide. JIFCC 2014;25:228-229.

4. Lau D. Tackling Peer Review: How to Improve Reviews and Minimize Abuse. Canadian Journal of Diabetes 2016;40(2):105-106. doi: 10.1016/j.jcjd.2016.02.004

5. Lee C, Sugimoto C, Zhang G, Cronin B. Bias in peer review. Journal of The American Society For Information Science And Technology 2012;64(1). doi: https://doi.org/10.1002/asi.22784

6. Smith R. Peer Review: A Flawed Process at the Heart of Science and Journals. Journal of The Royal Society of Medicine 2006;99(4):178-182. doi: 10.1177/014107680609900414

7. Tomkins A, Zhang M, Heavlin W. Reviewer bias in single- versus double-blind peer review. Proceedings Of The National Academy of Sciences 2017;114(48):12708-12713. doi: $10.1073 /$ pnas. 1707323114

8. Walker R, Barros B, Conejo R, Neumann K, Telefont M. Personal attributes of authors and reviewers, social bias and the outcomes of peer review: a case study. F1000 research 2015;4:21. doi: 10.12688/f1000research.6012.2

9. Zherebchevsky S, Ceo N, Tanaka M, Jank D, Stead S, Smiraglia R. American Society for Information Science \& Technology 2008 Annual Meeting contributed poster. Proceedings of The American Society For Information Science And Technology 2008;45(1):1-5. doi: 10.1002/meet.2008.14504503117

10. Gender bias in peer review - opening up the black box, 2019. [Blog]. Retrieved from https://blogs.lse.ac.uk/impactofsocialsciences/2019/03/0 8/gender-bias-in-peer-review-opening-up-the-blackbox/ 